\author{
Universitäts-Kinderkliniken Zürich \\ Medizinische Klinik \\ Direktor: Prof. Dr. med. F.H. Sennhauser \\ Abteilung Kardiologie \\ Leiter: Prof. Dr. med. U. Bauersfeld
}

Arbeit unter der Leitung von Dr. med. C. Balmer

Cardiomyopathy in newborns and infants: a broad spectrum of aetiologies and poor prognosis

\title{
INAUGURAL-DISSERTATION
}

zur Erlangung der Doktorwürde der Medizinischen Fakultät der Universität Zürich

\author{
vorgelegt von \\ Andrea Claudia Badertscher \\ von Zäziwil BE
}

Genehmigt auf Antrag von Herrn Prof. Dr. med. F.H. Sennhauser

Zürich 2009 
Publikation in:

Acta Paediatrica 2008, Vol. 97, Issue 11, p. 1523-1528 


\section{Cardiomyopathy in newborns and infants: a broad spectrum of aetiologies and poor prognosis}

Andrea Badertscher' ', Urs Bauersfeld', Urs Arbenz' ${ }^{1}$ Matthias R. Baumgartner ², Albert Schinzel’3, Christian Balmer (christian.balmer@kispi.uzh.ch)

1.Division of Cardiology, University Children's Hospital, Zurich, Switzerland

2.Division of Metabolic Diseases, University Children's Hospital, Zurich, Switzerland

3.Institute of Medical Genetics, University of Zurich, Zurich, Switzerland

Keywords

Cardiomyopathy, Echocardiography, Infant, Neonate

Correspondence

Christian Balmer, M.D., University Children's Hospital, Steinwiesstrasse 75, CH-8032 Zurich,

Switzerland

Tel: $+41-442667111$

Fax: $+41-442667981$

Email: christian.balmer@kispi.uzh.ch

Received

26 February 2008; revised 5 May 2008; accepted

30 June 2008.

DOI:10.1111/.j.1651-2227.2008.00957.x

\section{Abstrac}

Aim: This study set out to describe the initial clinical findings, morbidity, mortality and aetiology of infant cardiomyopathy focusing on potential risk factors for an adverse outcome.

Methods: We retrospectively analysed clinical and laboratory findings of all patients diagnosed at our institution from 1995 to 2004 with cardiomyopathy within their first year of life.

Results: Of the 35 patients, cardiomyopathy was classified as dilated in 18, hypertrophic in 14 and unclassified in 3. The aetiologies were genetic syndromes (8), metabolic diseases (5), familial isolated cardiomyopathy (3) and myopathy (1). During a median follow-up of 1.5 years (range 09 years), 13 patients died from progressive heart failure and two underwent heart transplants. Estimated survival and freedom from transplant was $69,66,58$ and 50\% after 0.5, 1, 2 and 6 years, respectively. Patients with severe heart failure symptoms within the first month of life had significantly worse outcomes than patients without heart failure symptoms.

Conclusion: High morbidity and poor prognosis result through progressive heart failure. Aetiology and clinical course are especially heterogeneous in infants. The most commonly identified aetiologies are genetic syndromes and metabolic diseases. A multidisciplinary approach is recommended for defining the aetiology and developing individual treatment strategies.

\section{INTRODUCTION}

Cardiomyopathy is a disease of the heart muscle charac terized by the presence of systolic or diastolic dysfunction or abnormal myocardial structure. The annual incidence is around 8 per 100000 within the first year of life (1). Cardiomyopathies are subdivided into hypertrophic, dilated, restrictive, arrhythmogenic right ventricular and unclassified cardiomyopathies (2).

In infants, cardiomyopathy often forms part of a systemic disease involving multiple organ systems, such as genetic syndromes, metabolic diseases and neuromuscular disorders (3-5)

Progression from the hypertrophic to the dilated form of cardiomyopathy is possible in one and the same patient. There are only a few patients in whom a causal therapy can be initiated. There is little published data about aetiology and clinical courses of cardiomyopathy in infants. Counselling and risk assessment may be difficult due to a lack of knowledge on the clinical course and prognostic factors. This study set out to identify predictors for an adverse outcome by critically assessing the clinical findings, morbidity, mortality and aetiology of all infants with cardiomyopathy, seen at our institution over the last 10 years.

\section{Abbreviations}

DCM, dilated cardiomyopathy; HCM, hypertrophic cardiomyopathy; UCM, unclassified cardiomyopathy.

\section{PATIENTS AND METHODS}

This study is a retrospective analysis in a single tertiary care centre. We included all consecutive infants and neonates with cardiomyopathy diagnosed within the first year of life and born in the years from 1995 to 2004. Patients with secondary cardiomyopathy due to longstanding tachycardia, cardiac surgery or elevated ventricular pressures were excluded from the study.

Patients were divided into five groups: dilated, hypertrophic, restrictive, right ventricular arrhythmogenic and unclassified cardiomyopathies (such as non-compaction) in accordance with the WHO classification (2). Dilated cardiomyopathy (DCM) is characterized by dilatation and/or impaired contraction of the left ventricle or both ventricles (2). A left ventricular end-diastolic dimension of more than 2 standard deviations above the mean normal values (6) was considered as dilated. An ejection fraction of 55\% or less or a shortening fraction of $28 \%$ or less was regarded as impaired contraction (7). Hypertrophic cardiomyopathy (HCM) was defined by a septal or posterior wall thickness that was more than 2 standard deviations above the mean normal thickness (6).

Patients were subdivided according to aetiology as follows: genetic syndromes, metabolic diseases, neuromuscular disease, familial isolated cardiomyopathy, inflammation and unknown aetiology (8).

The genetic syndromes were subdivided into three groups. (1) Classified syndrome: the patient shows dysmorphic findings typical of a known syndrome, and genetic analysis 


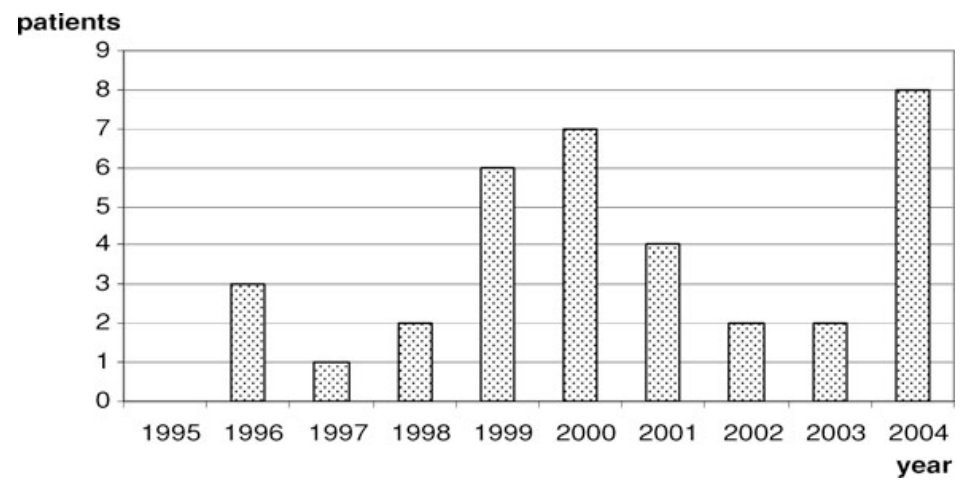

Figure 1 Distribution of the patients over the 10 years of the study period.

confirmed the diagnosis. (2) Suspected known syndrome: the patient shows dysmorphic findings typical for a known syndrome, but genetic confirmation was either not feasible (because the responsible gene is still unknown) or no mutation in the gene known to cause the syndrome was detected. (3) Suspected unknown syndrome: the patient shows multiple dysmorphic findings but a recognizable syndrome could not be classified.

Heart failure was defined as severe when catecholamines and/ or intubation was required.

The study was approved by the local hospital ethical committee, and written informed consent was obtained for the data collection.

For statistical analysis, we used SPSS 14.0 for Windows. Patient groups were compared using the Mann-Whitney $U$ test or crosstabs and chi-square test. p-value $<0.05$ was defined as significant. Survival was calculated with KaplanMeier analysis. Echocardiographic values were compared using the $\mathrm{Z}$ score.

\section{RESULTS}

Type of cardiomyopathy

Over the 10-year-period, 35 infants presented with cardiomyopathy. Figure 1 shows the distribution of the cases over the 10 years. DCM and HCM were the two leading types of cardiomyopathy, while restrictive and right ventricular arrhythmogenic cardiomyopathies were not represented (Table 1). Three infants were in the unclassified cardiomyopathy (UCM) group: the first patient fulfilled the criteria for non-compaction (9). Genetic analysis failed to demonstrate a mutation characteristic for Barth syndrome. The second patient showed a small left ventricle with a spongy myocardium and moderately impaired ventricular function. His right ventricle was mildly enlarged and its function mildly impaired. The aetiology remained unknown, and he died at the age of 1 month. The third infant with UCM suffered from long-chain 3-hydroxyacyl-CoA dehydrogenase (LCHAD) deficiency. His ventricular myocardium was neither dilated nor hypertrophic but the left ventricular function was severely impaired with a shortening fraction of $17 \%$ He died at the age of 3 days

\section{Aetiology}

In $51 \%(n=18)$ of the patients the aetiology of the cardiomyopathy remained unknown. The identified aetiologies (49\%) were all genetic (Fig. 2). Genetic syndromes and metabolic diseases are the most frequent aetiologies (Table 2).

\begin{tabular}{|c|c|c|c|c|c|}
\hline & & DCM & $\mathrm{HCM}$ & UCM & ALL \\
\hline \multirow[t]{4}{*}{ Demographic data } & Number of patients & 18 & 14 & 3 & 35 \\
\hline & Percentage of all & 51 & 40 & 9 & 100 \\
\hline & $\operatorname{Sex}(F / M)$ & 1.25 & 0.27 & 2.00 & 0.75 \\
\hline & Age at diagnosis (days): median (range) & $28(0-304)$ & $75(0-332)$ & $3(0-148)$ & $26(0-332)$ \\
\hline \multirow[t]{2}{*}{ Outcome } & Death or transplant: N (\%) & $8(44)$ & $4(29)$ & $3(100)$ & $15(43)$ \\
\hline & Age at death/transplant (days): median (range) & $86(2-1907)$ & $94(53-118)$ & $31(3-520)$ & $83(2-1907)$ \\
\hline \multirow[t]{3}{*}{ Symptoms of heart failure } & Severe heart failure: N (\%) & $8(44.5)$ & $3(21)$ & $3(100)$ & $14(40)$ \\
\hline & Mild or moderate heart failure: $\mathrm{N}(\%)$ & $8(44.5)$ & $6(43)$ & $0(0)$ & $14(40)$ \\
\hline & No heart failure: N (\%) & $2(11)$ & $5(36)$ & $0(0)$ & $7(20)$ \\
\hline
\end{tabular}

$\mathrm{DCM}$ = dilated cardiomyopathy; $\mathrm{HCM}$ = hypertrophic cardiomyopathy; $\mathrm{UCM}=$ unclassified cardiomyopathy. 


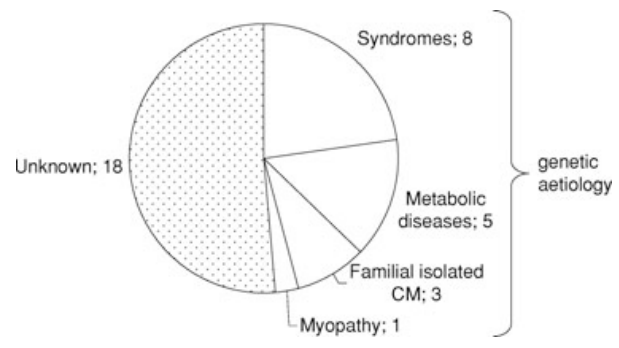

Figure 2 Aetiology of 35 patients with cardiomyopathy; number of patients.

With DCM, the aetiology remains unknown more frequently than for HCM (66\% vs. $29 \%$; p = 0.037, Table 2$)$. It was possible to assign patients with HCM to a genetic syndrome more frequently.

\section{Clinical presentation}

Heart failure was the most frequent reason for the first consultation in our cohort (Table 3). Heart failure, if present, was severe in most of the patients and required intubation and/or catecholamines in $25 / 28$ patients during subsequent follow-up. The DCM group had a high heart failure rate $(16 / 18)$, while more than a third of the patients with $\operatorname{HCM}(5 / 14)$ were without symptoms $(p=0.095)$. A total of $7 / 35$ patients remained free of any heart failure symptoms throughout the duration of the study.

A systolic murmur was present in 25/35 infants at the time of diagnosis. No correlation was found between heart auscultation and the severity, morphology or aetiology of the cardiomyopathy.
Dysmorphic features were present in 16/35 infants. In 13 of these patients, a confirmed or possible genetic aetiology was found (Table 2).

The ECG was normal in only four patients at first presentation and in one at the end of follow-up. The most common pathological finding was an unspecific ventricular repolarization abnormality (20/33). The voltage criteria for ventricular hypertrophy were fulfilled in 15 patients (DCM: 6/16, HCM: 8/11, UCM: 1/3).

The echocardiography at presentation of infants with DCM showed a median ejection fraction of 35\% (7-57\%) and a median shortening fraction of $15 \%(6-38 \%)$. There is a trend towards a lower initial shortening fraction in nonsurvivors compared with survivors having DCM (15 vs. 20\%; $\mathrm{p}=0.48$ ). The size of the left ventricle reached its maximum in most of the patients with DCM within the first year after diagnosis (Fig. 3). In HCM, the median Z score of posterior wall thickness was 3.6 at the beginning $(-0.4$ to 7.5$)$ and 3.5 ( 0 to 10.5$)$ at the end of the follow-up. Systolic function, as measured by shortening fraction and ejection fraction, was within the normal range in all patients with HCM; 6/14 patients with HCM had an outflow tract obstruction (5 left and 1 both outflow tracts).

\section{Outcome}

During a median follow-up time of 1.5 years (range 09 years), 13 patients died and 2 underwent heart transplant. Most of the patients died within the first 2 years of life (Fig. 4). There was a trend towards a better survival in patients with HCM (10/14) compared with the DCM group $(10 / 18)$ (Table 1). In the HCM group, all the patients who died suffered from a syndrome or from general myopathy and three of the four patients who died had an obstructed left ventricular outflow tract. The group of patients with

Table 2 Diagnosis, cardiac morphology and age of death or transplant of 35 patients with cardiomyopathy

\begin{tabular}{|c|c|c|c|c|c|c|c|}
\hline \multicolumn{4}{|c|}{ Aetiology of the cardiomyopathy } & $\mathrm{DCM}(\mathrm{N})$ & $\mathrm{HCM}(\mathrm{N})$ & UCM (N) & Age at death/transplant \\
\hline Genetic & Syndrome & Classified & Noonan & , & 1 & & $\begin{array}{l}\text { Alive } \\
4 \text { days }\end{array}$ \\
\hline & & Suspected known* & Noonan & & 2 & & \\
\hline & & & Costello & & 1 & & 3.9 months \\
\hline & & & Cantù syndrome & & 1 & & Alive \\
\hline & & Suspected unknown ${ }^{\dagger}$ & Dysmorphy syndrome & & 2 & & $2.7 ; 3.4$ months \\
\hline & Metabolic disease & & Barth syndrome & 1 & & & 2 days \\
\hline & & & LCHAD deficiency & & & 1 & 3 days \\
\hline & & & ATP synthase deficiency & & 1 & & \\
\hline & & & Defects in complex I and IV of respiratory chain & & 1 & & Alive \\
\hline & & & Unclassified metabolic disease & 1 & & & 4.3 months \\
\hline & Familial isolated & & & 3 & & & $1.3 ; 62$ months; alive \\
\hline & Myopathy & & Steinert's dystrophia myotonica & & 1 & & 1.7 months \\
\hline Unknown & & & & 12 & 4 & 2 & \\
\hline Total & & & & 18 & 14 & 3 & \\
\hline
\end{tabular}

*Patient shows dysmorphic findings typical for a known syndrome, but genetic confirmation was either not feasible (because the responsible gene is still unknown) or no mutation in the gene known to cause the syndrome was detected.

†Patient shows multiple dysmorphic findings but a recognizable syndrome could not be classified.

ATP = adenosine triphosphate; DCM = dilated cardiomyopathy; HCM = hypertrophic cardiomyopathy; LCHAD = long-chain 3-hydroxyacyl-CoA dehydrogenase deficiency; UCM = unclassified cardiomyopathy. 
Table 3 Reasons for referral in 35 patients with cardiomyopathy

\begin{tabular}{lllll} 
& DCM (N) & HCM (N) & UCM (N) & All (N) \\
\hline Heart failure & 10 & 7 & 2 & 19 \\
Systolic murmur & 1 & 4 & 0 & 5 \\
Routine antenatal ultrasound & 1 & 1 & 0 & 2 \\
Acute life-threatening event & 2 & 0 & 1 & 3 \\
Metabolic disease & 1 & 1 & 0 & 2 \\
Family history of cardiomyopathy & 2 & 0 & 0 & 2 \\
Genetic syndrome & 1 & 1 & 0 & 1 \\
Routine oncological screening & 0 & 14 & 3 & 35 \\
Total & 18 & & 0 \\
\hline
\end{tabular}

$\mathrm{DCM}$ = dilated cardiomyopathy; $\mathrm{HCM}$ = hypertrophic cardiomyopathy; $\mathrm{UCM}$ = unclassified cardiomyopathy

severe heart failure symptoms within the first month of life had a significantly worse outcome than the rest of the study population $(\mathrm{p}<0.0001)$. All the patients who remained asymptomatic throughout the study period survived. In all 13 patients who died, the cause of death was progressive heart failure. There was a trend towards a worse outcome in patients who were diagnosed early: five of eight deaths from DCM and all four deaths from HCM occurred in patients who were diagnosed within the neonatal period.

\section{DISCUSSION}

This report gives a detailed picture of the aetiology, clinical pattern, cardiac morphology and outcome of cardiomyopa- thy in 35 patients diagnosed within the first year of life In our study population, the frequency of the various morphologies of cardiomyopathy was similar to that reported in other series $(10,1)$. DCM was the most common type, followed by HCM. Restrictive and right ventricular arrhythmogenic cardiomyopathies are rarely diagnosed in infants $(10-12)$ and were not represented in our cohort.

The incidence of HCM is lower when compared with older children or adults (10). This may be explained by the later occurrence of symptoms such as heart failure in HCM compared to DCM (Table 1). The normal thickness of the infant ventricular myocardium also shows a much wider variation range in relation to the size of the heart than in older patients (6). For this reason, it is possible that the true

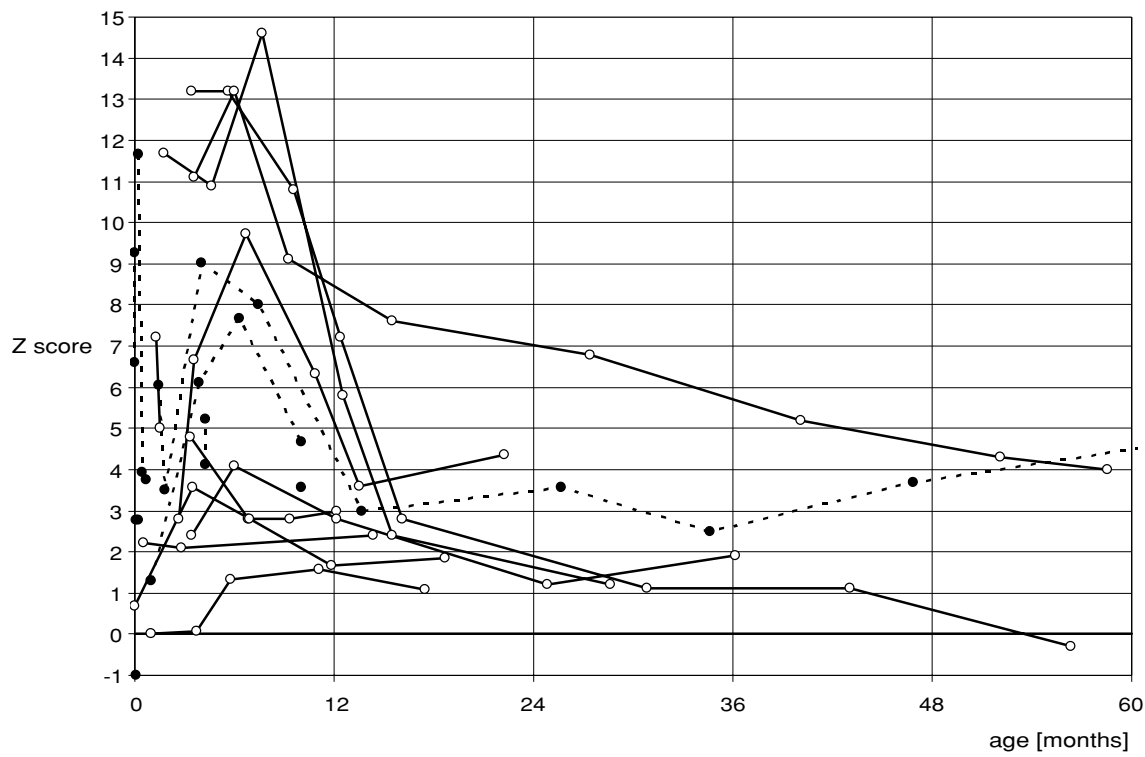

Figure 3 Follow-up of left ventricular size (left ventricular end-diastolic diameter) in survivors $(N=10)$ and non-survivors ( $N=8^{*}$, dashed line) with dilated cardiomyopathy.

*Patients with a very short follow-up may only have points instead of graphs. 


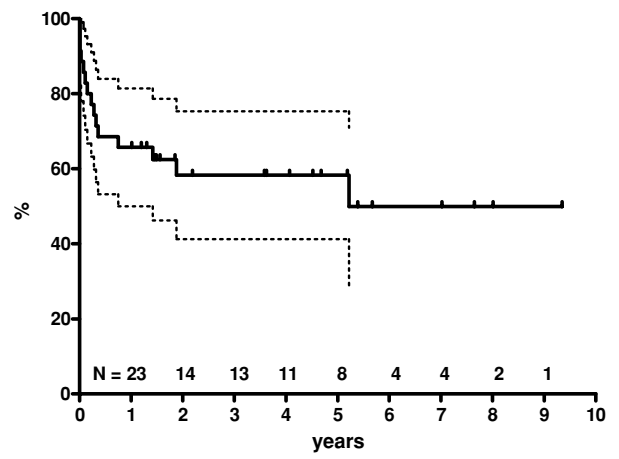

Figure 4 Kaplan-Meier estimates of freedom from death or transplant in 35 patients with cardiomyopathy ( $95 \%$ confidence intervals and numbers at risk).

incidence of HCM in infants is still being underestimated. The existence of a male predominance of $69-75 \%$ in HCM $(10,4)$ is also supported by our data.

Finding the aetiology of a cardiomyopathy can be timeconsuming and frustrating. The reported success rate is around $30 \%(13)$ and it is $50 \%$ in our study. Nevertheless, it is important to undertake every effort to establish the aetiology of the cardiomyopathy because there may be a causative therapy available. Also, specific screening of other members of the family and meaningful counselling of the parents regarding the risk of recurrence is possible only if the aetiology of the cardiomyopathy is known. It may also help in forecasting the further course of the disease: in our study population, the clinical course and the age of death of patients with known aetiologies were within the previously published and predicted range for the respective disease in all patients (Table 2) (14-19).

Recently published guidelines may assist in achieving a systematic approach in diagnosing cardiomyopathies (8), and the early involvement of sub-specialists in metabolic, genetic and neuromuscular diseases is helpful in focussing these examinations on clinical suspicion and in keeping costs low. The two leading groups of known aetiologies, namely genetic syndromes and metabolic diseases (Table 2), must always be considered when searching for the aetiology of cardiomyopathy in infants.

In 7 of the 18 patients with unknown aetiologies, myocarditis was suspected but not proved. Neither the patient's history nor laboratory testing will help prove or exclude myocardial inflammation, and endomyocardial biopsy is still the gold standard (13). We in our department are reluctant to perform an endomyocardial biopsy in infants, because of its limitations in sensitivity (sampling error) and specificity, and also the inherent risk of complications.

The prognosis of neonates and infants with symptomatic cardiomyopathy is poor. Many patients suffer from severe heart failure and the mortality rate is high (Table 1). Most of the deaths occur within 2 years after the first presentation
(Fig. 4). Patient selection, however, may have influenced this bad outcome.

Because of the small number of patients and the retrospective study design, we are not able to make further statements about risk factors for death or transplant, but we observed the following trends, which concord with previously described series (5): mortality was higher in patients with DCM than in patients with HCM (44 vs. $29 \%$ ). The severity of the disease at presentation, as represented by the symptoms and the pathologic measurements in echocardiography scans, also correlated with an adverse outcome. Severe heart failure at the time of diagnosis results in a higher mortality rate compared with the group as a whole. In patients with DCM, the shortening fraction of non-survivors was lower than that for the survivors ( 15 vs. $20 \%$ ). The sex, age at presentation, ECG and laboratory findings did not influence the outcome in our population.

The size of the left ventricle in patients with DCM at the first presentation is not a good predictor for an adverse outcome: even patients with severely dilated left ventricles are able to survive, or even normalize their ventricular size and function (Fig. 3). The reason of the improvement of the left ventricular size in patients with DCM during the follow-up cannot be explained by this retrospective study. It does, however, suggest intermittent rather than chronic or persistent damage to the myocardium; an inflammation process with subsequent myocardial recovery and remodelling, as seen in myocarditis, may be the reason for the DCM in many of these patients.

The incidence of sudden cardiac death in patients with diagnosed cardiomyopathy is surprisingly low. It did not occur in our series and is reported to occur in only $1.3 \%$ of all paediatric patients listed for heart transplant (20). The true incidence of sudden cardiac death in paediatric patients with cardiomyopathy is not, however, available. Other studies reported an incidence of $1 \%$ in children with HCM (4) and $11 \%$ in children with DCM (21). Sudden death is the first sign of cardiomyopathy in as many as $3.5 \%$ of the patients (22).

To conclude, cardiomyopathy in infants is a very severe disease with unspecific symptoms and a high mortality, especially when presenting in the first month of life. A multidisciplinary approach is recommended as there are various rare aetiologies, which may lead to cardiomyopathy with the two leading aetiologies being genetic syndromes and metabolic diseases. History, clinical examination and laboratory testing will be successful in many patients with $\mathrm{HCM}$ and in some patients with DCM.

\section{References}

1. Lipshultz SE, Sleeper LA, Towbin JA, Lowe AM, Orav EJ, Cox GF, et al. The incidence of pediatric cardiomyopathy in two regions of the United States. N Engl J Med 2003; 348 : 1647-55.

2. Richardson P, McKenna W, Bristow M, Maisch B, Mautner B, O'Conell J, et al. Report of the 1995 World Health Organization/ International Society and Federation of 
Cardiology Task Force on the definition and classification of cardiomyopathies. Circulation 1996; 93: 841-2.

3. Kohlschütter A, Hausdorf G. Primary (genetic) cardiomyopathies in infancy. A survey of possible disorders and guidelines for diagnosis. Eur J Pediatr 1986; 145 454-9.

4. Nugent AW, Daubeney PE, Chondros P, Carlin JB, Colan SD Cheung M, et al. Clinical features and outcomes of childhood hypertrophic cardiomyopathy. Circulation 2005; 112 1332-38.

5. Towbin JA, Lowe AM, Colan SD, Sleeper LA, Orav EJ, Clunie $\mathrm{S}$, et al. Incidence, causes and outcomes of dilated cardiomyopathy in children. JAMA 2006; 296: 1867-76.

6. Kampmann C, Wiethoff CM, Wenzel A, Stolz G, Betancor M, Wippermann C-F, et al. Normal values of M mode echocardiographic measurements of more than 2000 healthy infants and children in central Europe. Heart 2000; 83 $667-72$.

7. Gutgesell HP, Paquet M, Duff DF, McNamara DG. Evaluation of left ventricular size and function by echocardiography. Results in normal children. Circulation 1977; 56: 457-62.

8. Schwartz ML, Cox GF, Lin AE, Korson MS, Perez-Atayde A, Lacro RV, et al. Clinical approach to genetic cardiomyopathy in children. Circulation 1996; 94: 2021-38.

9. Jenni R, Oechslin E, Schneider J, Attenhofer Jost C, Kaufmann P A. Echocardiographic and pathoanatomical characteristics of isolated left ventricular non-compaction: a step towards of isolated left ventricular non-compaction: a step towards 666-71.

10. Arola A, Jokinen E, Ruuskanen O, Saraste M, Pesonen E, Kuusela A, et al. Epidemiology of idiopathic cardiomyopathie in children and adolenscents. Am J Epidemiol 1997; 146: 385-93.

11. Fenton MJ, Chubb H, McMahon AM, Rees P, Elliott MJ, Burch M. Heart and heart-lung transplantation for idiopathic restrictive cardiomyopathy in children. Heart 2006; 92 $85-9$

12. Hulot JS, Jouven X, Empana JP, Frank R, Fontaine G. Natura history and risk stratification of arrhythmogenic right ventricular dysplasia/ cardiomyopathy. Circulation 2004; 110: 1879-84

13. Cox GF, Sleeper LA, Lowe AM, Towbin JA, Colan SD, Orav EJ, et al. Factors associated with establishing a causal diagnosis for children with cardiomyopathy. Pediatrics 2006; 118: 1519-31.

14. Barth PG, Valianpour F, Bowen VM, Lam J, Duran M, Vaz FM, et al. X-linked cardioskeletal myopathy and neutropenia (Barth syndrome): an update. Am J Med Genet 2004; 126: 349-54.

15. Den Boer ME, Wanders RJ, Morris AA, Ijlst L, Heymans HS, Wijburg FA. Long-chain 3-hydroxyacyl-CoA dehydrogenase deficiency: clinical presentation and follow-up of 50 patients. Pediatrics 2002; 109: 99-104.

16. Rasmussen SA, Wong LYC, May KM, Friedman JM Population-based analyses of mortalitiy in trisomy 13 and trisomy 18. Pediatrics 2003; 111: 777-84.

17. Scaglia F, Towbin JA, Craigen WJ, Belmont JW, Smith EO, Neish SR, et al. Clinical spectrum, morbidity, and mortality in 113 pediatric patients with mitochondrial disease. Pediatrics 2004; 114: 925-31.

18. Tartaglia M, Kalidas K, Shaw A, Song X, Musat DL, Van Der Burgt I, et al. PTPN11 mutations in Noonan syndrome: molecular spectrum, genotype-phenotype correlation, and phenotypic heterogeneity. Am J Hum Genet 2002; 70: $1555-63$

19. Towbin JA, Lipshultz SE. Genetics of neonatal cardiomyopathy. Curr Opin Cardiol 1999; 14: 250-62.

20. Rhee EK, Canter CE, Basile S, Webber SA, Naftel DC. Sudden death prior to pediatric heart transplantation: would implantable defibrillators improve outcome? J Heart Lung Transplant 2007; 26: 447-52.

21. Burch M, Siddiqi SA, Celermajer DS, Scott C, Bull C, Deanfield JE. Dilated cardiomyopathy in children: Deanfield JE. Dilated cardiomyopathy in children:

22. Nugent AW, Daubeney PE, Chondros P, Carlin J B, Cheung $\mathrm{M}$, Wilkinson LC, et al. The epidemiology of childhood cardiomyopathy in Australia. N Engl J Med 2003; 348 : $1639-46$ 


\section{Curriculum vitae}

\section{Andrea Claudia Badertscher}

Geburtstag:

Geburtsort:

30. Dezember 1983

Zivilstand:

Zürich

Heimatort:

ledig

Zäziwil, Kanton Bern

\section{Weiterbildung:}

Seit 2009

Assistentenstelle Chirurgie

Ospedale Regionale

di Locarno

\section{Ausbildung:}

$\begin{array}{clr}10 / 2008 & \text { Staatsexamen } & \text { Universität Zürich } \\ 2002-2008 & \text { Medizinstudium } & \text { Universität Zürich } \\ 02-06 / 2006 & \begin{array}{l}\text { Austauschsemester mit ERASMUS } \\ \text { in Italien }\end{array} & \begin{array}{r}\text { Università degli } \\ \text { studi di Trieste }\end{array} \\ 1998-2002 & \begin{array}{l}\text { Mathematisch-Naturwissenschaftliches } \\ \text { Gymnasium Rämibühl }\end{array} & \text { Zürich } \\ 1996-1998 & \text { Sekundarschule } & \text { Au-Wädenswil } \\ 1990-1996 & \text { Primarschule } & \text { Au-Wädenswil }\end{array}$

